\title{
Vitamin D Deficiency as a Cause of Hip Fractures in the Elderly
}

\author{
Lambros Athanassiou ${ }^{1}$, Panagiotis Athanassiou ${ }^{2}$, Alexandros Pastroudis ${ }^{3}$, Alexandros Samolis ${ }^{4}$, Panagiotis \\ Giavopoulos ${ }^{4}$, Ifigenia Kostoglou-Athanassiou ${ }^{5}$ and Georgios Troupis ${ }^{4}$
}

${ }^{1}$ Department of Rheumatology, Ascelepion Hospital, Voula, Athens, Greece

${ }^{2}$ Department of Rheumatology, St. Paul's Hospital, Thessaloniki, Greece

${ }^{3} 6$ th Department of Orthopedics, Asclepeion Hospital, Voula, Athens, Greece

${ }^{4}$ Department of Anatomy, Medical School, University of Athens, Greece

${ }^{5}$ Department of Endocrinology, Asclepeion Hospital, Voula, Athens, Greece

Submission: June 29, 2021; Published: July 14, 2021

*Corresponding author: Dr. Panagiotis Athanassiou, Patriarchou Ioakim 3, Thessaloniki, GR54622, Greece

\section{Abstract}

Objectives: Vitamin D is a hormone which is instrumental for bone metabolism and bone health. It induces calcium absorption from the gastrointestinal tract and contributes to bone health. Vitamin D deficiency leads to osteomalacia, however, if deficiency is severe it contributes to the development of secondary hyperparathyroidism and thus induces osteoporosis. The aim was to describe a cohort of patients hospitalized for hip fracture who were diagnosed with severe vitamin D deficiency.

Methods: A cohort of patients hospitalized for a hip fracture is described. Patients were elderly, age $84.1 \pm 1.42$ years (range 75-93) and frail. Within this cohort 12 were male and 8 females. In this cohort 25(OH)D3 levels were measured. Bone mineral density was also measured by dual energy X-ray absorptiometry either in the contralateral hip or in the lumbar spine. Observations were also performed in a control group matched for age and sex.

Results: In a cohort of elderly patients hospitalized for hip fracture $25(\mathrm{OH}) \mathrm{D} 3$ levels were $9.26 \pm 0.54 \mathrm{ng} / \mathrm{ml}(\mathrm{mean}+\mathrm{SEM})$ as compared to $27.78 \pm 2.15 \mathrm{ng} / \mathrm{ml}$ in the control group ( $\mathrm{p}<0.001$, Student's $\mathrm{t}$ test). Bone mineral density as defined by $\mathrm{T}$ score was $-3.09 \pm 0.09$ in the cohort of elderly patients as opposed to $-2.48 \pm 010$ in the control group ( $\mathrm{p}<0.001$, Student's $\mathrm{t}$ test).

Conclusion: Severe vitamin D deficiency was observed in a cohort of elderly patients hospitalized for hip fracture. Vitamin D deficiency is accompanied by osteomalacia. However, secondary hyperparathyroidism ensues and leads to increased bone resorption. Augmented bone resorption leads to osteoporosis which is a cause of fractures. Vitamin D deficiency affects muscle function, and it may lead to falls. In conclusion, severe vitamin D deficiency may contribute to the development of falls and subsequent hip fractures in elderly patients. Elderly patients, especially if homebound or residents in long-term facilities should be screened for vitamin D deficiency and supplemented with daily small or medium doses of vitamin D.

Keywords: Vitamin D; Hip fracture; Osteoporosis; Osteomalacia; Bone mineral density

\section{Introduction}

Vitamin D is a hormone which is involved in bone metabolism [1-3]. It induces calcium absorption from the gastrointestinal tract and is instrumental for bone health, as it is involved in bone mineralization [4-6]. If vitamin D deficiency ensues osteomalacia evolves [5,7]. However, as vitamin D deficiency becomes severe and chronic, calcium levels decrease, and parathyroid hormone levels increase. Thus, severe vitamin D deficiency leads to secondary hyperparathyroidism. Secondary hyperparathyroidism leads to osteoporosis [8,9]. Osteoporosis may lead to fractures [8]. Hip fractures are a major factor of morbidity and mortality in the elderly population. The aim was to describe vitamin D levels in a group of elderly patients hospitalized for a hip fracture.

\section{Methods}

In a cohort of elderly patients hospitalized for a hip fracture $25(\mathrm{OH}) \mathrm{D}_{3}$ levels and bone mineral density by dual energy $\mathrm{X}$ ray absorptiometry were determined. Observations were also performed in a control group of elderly patients matched for age and sex. $25(\mathrm{OH}) \mathrm{D}_{3}$ was estimated by an electrochemiluminescence binding assay (Elecsys Vitamin D total, for cobas e 411 analyzer, Roche Diagnostics GmbH, Mannheim, Germany). The assay was based on a competition principle. In summary, after a first incubation, so that the bound 25(OH)D could be released from the vitamin D binding protein, a second incubation was performed. 


\section{Orthopedics and Rheumatology Open Access Journal (OROAJ)}

During the second incubation the pretreated sample was incubated with a ruthenium labeled vitamin D binding protein. Thus, a complex was formed between 25(OH)D and the ruthenium labeled vitamin D binding protein, the ruthenylated vitamin D binding protein. Thereafter a third incubation was performed. During the third incubation streptavidin microparticles and vitamin D labeled with biotin were added and unbound ruthenium labeled vitamin D binding proteins became occupied. A complex consisting of the ruthenylated vitamin D binding protein and the biotinylated vitamin D was formed and it was bound to the solid phase of the assay via interaction of biotin and streptavidin. The reaction mixture was then aspirated into the cell where the microparticles were magnetically captured onto the surface of an electrode. Unbound substances were then removed. Application of a voltage to the electrode then induced a chemiluminescent emission which was detected by a photomultiplier. The sensitivity of the assay was $10.03 \mathrm{nmol} / \mathrm{L}$. The within run $\mathrm{CV}$ of the assay ranged from $3.1 \%$ at $70.0 \mathrm{nmol} / \mathrm{L}$ to $7.8 \%$ at $16.9 \mathrm{ng} / \mathrm{ml}$.

\section{Results}

In a cohort of elderly patients hospitalized for hip fracture $25(\mathrm{OH}) \mathrm{D}_{3}$ levels were $9.26 \pm 0.54 \mathrm{ng} / \mathrm{ml}$ (mean+SEM) as compared to $27.78 \pm 2.15 \mathrm{ng} / \mathrm{ml}$ in the control group ( $\mathrm{p}<0.001$, Student's $\mathrm{t}$ test) (Figure 1). Bone mineral density as defined by $\mathrm{T}$ score was $-3.09 \pm 0.09$ in the cohort of elderly patients as opposed to $-2.48 \pm 010$ in the control group ( $p<0.001$, Student's $t$ test) (Figure 2).

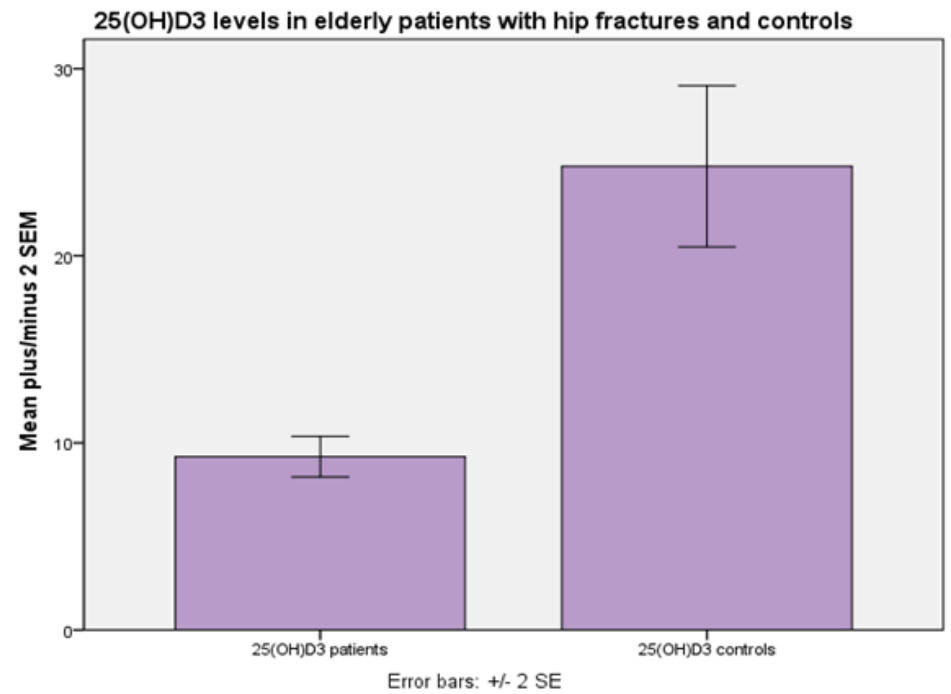

Figure 1: $25(\mathrm{OH}) \mathrm{D}_{3}$ levels in a group of elderly patients with hip fractures and controls $(p<0.001$, Student's $t$ test).

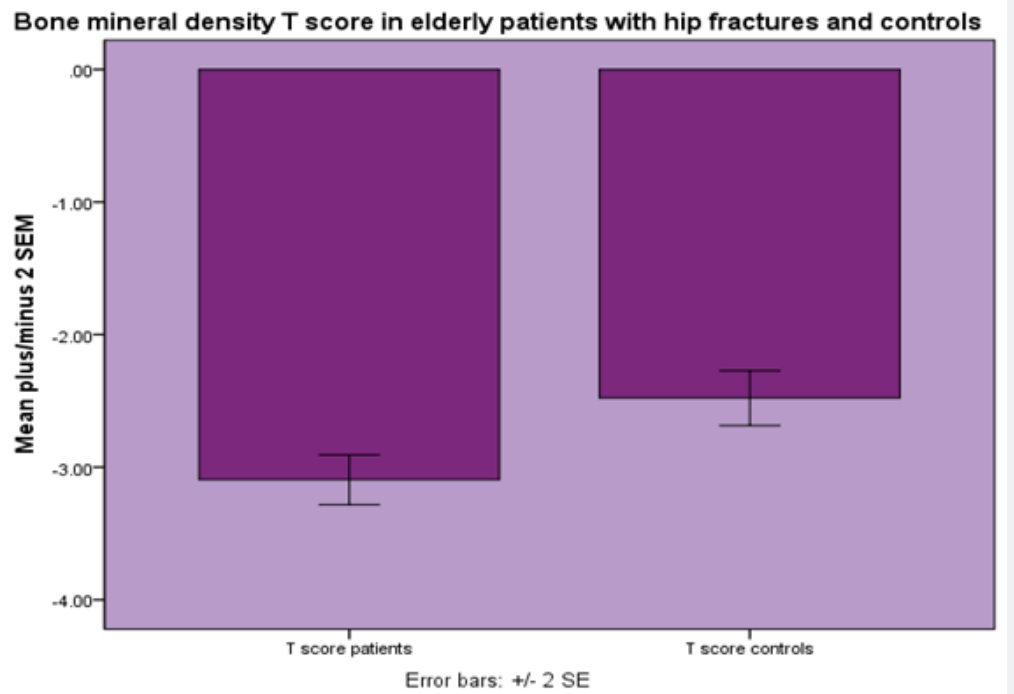

Figure 2: Bone mineral density T score in elderly patients with hip fractures and controls $(p<0.001$, Student's $t$ test). 


\section{Discussion}

In a group of elderly patients hospitalized for a hip fracture very low levels of vitamin D were observed. Vitamin D deficiency may lead to fractures. In elderly individual's vitamin D levels should be estimated, and vitamin D supplementation should be encouraged. Vitamin D is instrumental for bone metabolism and bone health. It induces bone mineralization and thus contributes to the optimum structure and function of the bone. Additionally, vitamin D affects the function of muscles [10-13]. Vitamin D deficiency adversely affects muscle function and may lead to falls ${ }^{11}$. Falls are a major factor leading to fractures $[14,15]$. Falls are responsible for at least $80 \%$ of fractures in the elderly. Fractures are a major factor for morbidity and mortality in the elderly [16].

The main effect of the active vitamin $\mathrm{D}$ metabolite $1,25(\mathrm{OH})_{2} \mathrm{D}_{3}$ is to stimulate the absorption of calcium from the gut. The consequences of vitamin D deficiency are secondary hyperparathyroidism and bone loss, leading to osteoporosis and fractures, mineralization defects, which may lead to osteomalacia in the long term, and muscle weakness, causing falls and fractures. As vitamin D deficiency leads to secondary hyperparathyroidism, it may lead to increased bone resorption, low bone mineral density and osteoporosis. Decreased vitamin D levels are associated with increased bone turnover and decreased bone mineral density. Vitamin D supplementation may decrease bone turnover and increase bone mineral density. Several randomized placebocontrolled trials with vitamin D and calcium showed decreased fracture incidence. When patients with osteoporosis are treated with an antiosteoporotic agent, they should receive a vitamin D and calcium supplement.

Elderly individuals, especially those who are homebound or those who are dwelling in long-term care facilities should be screened for vitamin D deficiency. Vitamin D is produced within the skin from 7-dehydrocholesterol under the influence of ultraviolet irradiation. Therefore, homebound people, who are not exposed to the sun may have very low levels of vitamin D within their blood. In elderly individuals the most important problem is the prevention of falls and fractures $[14,17,18]$, as falls may lead to loss of independence or death. Vitamin D deficiency is observed in a large part of the population of elderly people, especially women, who live in moderate climate countries, due to a reduced amount of vitamin D in the diet, as small fish are not readily available for consumption and reduced content of 7-dehydrocholesterol, which causes decreased skin synthesis. Seasonality may also affect $25(\mathrm{OH}) \mathrm{D}_{3}$ concentration, lowest levels observed during the winter and spring [19-25]. Lack of sun exposure affects more women than men. Various environmental factors increase the risk of vitamin D deficiency in the elderly. These are poor environmental conditions, low economic status, low educational level, smoking, reduced physical activity and poor overall health. The presence of gastrointestinal diseases may also contribute to vitamin D deficiency due to malabsorption. The presence of renal disease also affects vitamin D status as it affects the hydroxylation of vitamin $\mathrm{D}$ and the production of active metabolites.

Vitamin D supplementation for the prevention of falls in the elderly has been discussed in the literature [11,26-30]. It was shown that vitamin D supplementation should be performed with daily small or medium doses of vitamin $\mathrm{D}$ as these doses have been shown to decrease falls [27].

\section{Conclusion}

In conclusion, it was shown that in elderly patients with hip fractures low $25(\mathrm{OH}) \mathrm{D}_{3}$ levels are prevalent. Low vitamin D levels in these patients may contribute to increased bone resorption due to secondary hyperparathyroidism and consequently osteoporosis, poor muscle function, falls and fractures. Therefore, screening for vitamin D deficiency should be performed in elderly individuals, especially if they are homebound or residents in long-term care facilities. Vitamin D supplementation should be performed with daily small or medium doses of vitamin $D$ as these doses have been shown to decrease falls and fractures.

\section{References}

1. Holick MF (2007) Vitamin D deficiency. N Engl J Med 357(3): 266-281.

2. Holick MF (2017) The vitamin D deficiency pandemic: Approaches for diagnosis, treatment and prevention. Rev Endocr Metab Disord 18(2): 153-165.

3. Charoenngam N, Shirvani A, Holick MF (2019) Vitamin D for skeletal and non-skeletal health: What we should know. J Clin Orthop Trauma 10(6): 1082-1093.

4. Bouillon R, Marcocci C, Carmeliet G, Bikle D, John H White, et al. (2019) Skeletal and Extraskeletal Actions of Vitamin D: Current Evidence and Outstanding Questions. Endocr Rev 40(4): 1109-1151.

5. Tiefenbach M, Scheel M, Maier A, M Gehlen, M Schwarz-Eywill, et al. (2018) Osteomalacia-Clinical aspects, diagnostics and treatment. Z Rheumatol 77(8): 703-718.

6. Bikle DD (2012) Vitamin D and bone. Curr Osteoporos Rep 10(2): 151 159.

7. Uday S, Högler W (2017) Nutritional Rickets and Osteomalacia in the Twenty-first Century: Revised Concepts, Public Health, and Prevention Strategies. Curr Osteoporos Rep 15(4): 293-302.

8. Lips P, van Schoor NM (2011) The effect of vitamin D on bone and osteoporosis. Best Pract Res Clin Endocrinol Metab 25(4): 585-591.

9. Okazaki R (2016) Vitamin D insufficiency/deficiency: its clinical significance and treatment. Clin Calcium 26(2): 251-258.

10. Ksiazek A, Zagrodna A, Slowinska-Lisowska M (2019) Vitamin D, Skeletal Muscle Function and Athletic Performance in Athletes-A Narrative Review. Nutrients 11(8): 1800.

11. Dawson-Hughes B. Vitamin D and muscle function. J Steroid Biochem Mol Biol 173: 313-316.

12. Dzik KP, Kaczor JJ (2019) Mechanisms of vitamin D on skeletal muscle function: oxidative stress, energy metabolism and anabolic state. Eur J Appl Physiol 119(4): 825-839.

13. Garcia M, Seelaender M, Sotiropoulos A, Coletti D, Lancha AH, et al. (2019) muscle recovery, sarcopenia, cachexia, and muscle atrophy. Nutrition 60: 66-69. 
14. Ambrose AF, Cruz L, Paul G (2015) Falls and Fractures: A systematic approach to screening and prevention. Maturitas 82(1): 85-93.

15. Yeung SSY, Reijnierse EM, Pham VK, Marijke C Trappenburg, Wen Kwang Lim, et al. (2019) Sarcopenia and its association with falls and fractures in older adults: A systematic review and meta-analysis. Cachexia Sarcopenia Muscle 10(3): 485-500.

16. Johnell O, Kanis JA (2006) An estimate of the worldwide prevalence and disability associated with osteoporotic fractures. Osteoporos Int 17(12): 1726-1733

17. Dontas IA, Yiannakopoulos CK (2007) Risk factors and prevention of osteoporosis-related fractures. J Musculoskelet Neuronal Interact $7(3):$ 268-272.

18. Zhao R, Feng F, Wang X (2017) Exercise interventions and prevention of fall-related fractures in older people: a meta-analysis of randomized controlled trials. Int J Epidemiol 46(1): 149-161.

19. Wyskida M, Wieczorowska-Tobis K, Chudek J (2017) Prevalence and factors promoting the occurrence of vitamin D deficiency in the elderly. Postepy Hig Med Dosw (Online) 71(0): 198-204.

20. Fontanive TO, Dick NRM, Valente MCS, Vani Dos Santos Laranjeira, Marina Venzon Antunes, et al. (1992) Seasonal variation of vitamin D among healthy adult men in a subtropical region. Rev Assoc Med Bras 66(10): 1431-1436.

21. Niculescu DA, Capatina CAM, Dusceac R, Caragheorgheopol A, Ghemigian A, et al. (2017) Seasonal variation of serum vitamin D levels in Romania. Arch Osteoporos 12(1): 113.

22. Moon RJ, Curtis EM, Davies JH, Cooper C, Harvey NC (2017) Seasonal variation in Internet searches for vitamin D. Arch Osteoporos 12(1): 28.

This work is licensed under Creative Commons Attribution 4.0 License DOI: 10.19080/OROAJ 2021.18.555994
23. Hribar M, Hristov H, Gregorič M, Urška Blaznik, Katja Zaletel, et al. (2020) Nutrihealth Study: Seasonal Variation in Vitamin D Status Among the Slovenian Adult and Elderly Population. Nutrients 12(6): 1838.

24. Pourhassan M, Wirth R (2018) Seasonal Variation in Vitamin D Status among Frail Older Hospitalized Patients. J Frailty Aging 7(2): 95-99.

25. Shen M, Li Z, Lv D, Ge Yang, Ronghuan Wu, et al. (2020) Seasonal variation and correlation analysis of vitamin $\mathrm{D}$ and parathyroid hormone in Hangzhou, Southeast China. J Cell Mol Med 24(13): 73707377.

26. Gallagher JC (2016) Vitamin D and falls - the dosage conundrum. Nat Rev Endocrinol 12(11): 680-684.

27. Smith LM, Gallagher JC, Suiter C (2017) Medium doses of daily vitamin D decrease falls and higher doses of daily vitamin D3 increase falls: A randomized clinical trial. J Steroid Biochem Mol Biol 173: 317-322.

28. Bischoff-Ferrari HA, Willett WC, Wong JB, Giovannucci E, Dietrich T, et al. (2005) Fracture prevention with vitamin D supplementation: a meta-analysis of randomized controlled trials. Jama 293(18): 22572264.

29. Kannus P, Sievänen H, Palvanen M, Jarvinen T, Parkkari J (2005) Prevention of falls and consequent injuries in elderly people. Lancet 366(9500): 1885-1893.

30. Pfortmueller CA, Lindner G, Exadaktylos AK (2014) Reducing fall risk in the elderly: risk factors and fall prevention, a systematic review. Minerva Med 105(4): 275-281.

\section{Your next submission with Juniper Publishers will reach you the below assets}

- Quality Editorial service

- Swift Peer Review

- Reprints availability

- E-prints Service

- Manuscript Podcast for convenient understanding

- Global attainment for your research

- Manuscript accessibility in different formats

( Pdf, E-pub, Full Text, Audio)

- Unceasing customer service

Track the below URL for one-step submission https://juniperpublishers.com/online-submission.php 